\title{
Why does unemployment come in couples? An analysis of (un)employment and (non)employment homogamy tables for Canada, the Netherlands and the United States in the 1980s
}

\author{
WOUT ÜLTEE, JOS DESSENS AND WIM JANSEN
}

\begin{abstract}
In this paper we first raise the factual question of whether wives of unemployed husbands have a higher chance of unemployment than wives of employed husbands. Data for Australia, Canada, the Netherlands and the USA in the first half of the 1980s indicate that this indeed is the case. We then seek to explain this finding.

According to one explanation, (un)employment homogamy is a by-product of educational homogamy combined with a relation at the individual level between education and unemployment. Although the existence of educational homogamy in Canada, the Netherlands and the USA could be ascertained, and although in these countries unemployment is higher when education is lower, these findings could not fully explain the observed extent of (un)employment homogamy in these countries.

According to a more complex explanation, the phenomenon of (un)employment homogamy will disappear when we allow, after these effects of educacion, for similar effects of age and region. This explanation was tested for the USA, and did not explain the observed extent of (un)employment homogamy in this country either.

These findings show that labour market inequalities (unemployed persons have less education, are very young or very old, live in certain places) are aggravated by marriage market outcomes (educational and age homogamy). But, in addition, the finding of persistent couple effects suggests that, apart from labour market and marriage market effects, other processes taking plạce after marriage make for (un)employment homogamy.
\end{abstract}

\section{INTRODUCTION}

Until now, comparative mobility research has primarily sought answers to questions about father-son dyads, especially about father-to-son occupational mobility (cf. Miller, 1960; Grusky and Hauser, 1984). Given the name of this field, a focus on inter- and intragenerational mobility seems a matter of course. However, mobility monographs have long supplemented questions about father-son dyads with questions about husband-wife dyads. An example of an early monograph answering both mobility and homogamy questions is Glass (1954). A prime example of a contemporary study combining an interest in father-to-son mobility with an interest in the association between husband's and wife's occupation is Hout (1982).

Under full employment, a situation prevailing in most Western industrial societies in the period after World War II up to the first oil crisis, questions about inter- and intragenerational occupational mobility are fitting. Given presentday double digit unemployment in several Western industrial nations, questions about long-term unemployment deserve a high place on the agenda of contemporary mobility research. In the United Kingdom, Payne (1987) went so far as to explore the question whether unemployment runs in families, that is, to what 
TABLE 1 Employment status of husbands and wives in the Netherlands, Spring 1981

\begin{tabular}{lcccc}
\hline Eusbands & Employed & Unemployed & $\begin{array}{c}\text { Outside the } \\
\text { labour force }\end{array}$ \\
\hline $\begin{array}{l}\text { Employed } \\
\text { Unemployed }\end{array}$ & 2,367 & 237 & 4,795 & 7,399 \\
$\begin{array}{l}\text { Outside the } \\
\text { labour force }\end{array}$ & 71 & 22 & 192 & 289 \\
& 164 & 18 & 2,134 & 2,316 \\
\hline
\end{tabular}

$\mathrm{N}$ of cases has been set to 10,000 . The actual number was several times higher.

extent unemployment of earlier and later generations living in the same household is associated.

Questions about long-term unemployment belong to the field of stratification and mobility, as unemployment obviously is one dimension of stratification, and long-term unemployment just means lack of mobility along it. Long-term unemployed persons are one category of persons immobile in an intragenerational mobility table crossing (un)employment of persons at the beginning of a period against their (un)employment at its end. The present paper complements this approach by an analysis of tables crossing employment and unemployment of husbands and wives. It answers questions about a specific type of intermarriage, (un)employment homogamy. Do wives of unemployed husbands, compared to wives of employed husbands, have higher odds of unemployment? If so, how is this phenomenon to be explained? Similar questions are asked for (non)employment homogamy.

The next section of the paper empirically answers the question whether in three Western industrial nations in the early 1980 s (un)employment of husbands and wives is associated. The answer to this question being yes, the third section addresses the question of whether this association is a by-product of educational homogamy combined with a relation at the individual level between education and employment. The answer being no, the fourth section comes up with an empirical answer to the question of whether wives with relatively high education, whose husbands have the same level of education, have a lower probability of unemployment than wives with relatively low edu- cation whose husbands have relatively high education. A similar question is answered for husbands with relatively low and high education. The fifth section then addresses the question of whether (un)employment homogamy, apart from being a by-product of educational homogamy and an individual relation between education and employment, is in addition made up of two other by-products: one of age homogamy, together with an individual relation between age and employment, and one of the obvious fact that husband and wife live in the same place and of an individual relation between place of residence and employment. The final section sums up the paper's findings and discusses implications.

\section{(UN)EMPLOYMENT HOMOGAMY IN THREE WESTERN INDUSTRIAL NATIONS}

This section answers the descriptive question of to what extent (un)employment homogamy occurs. It applies an imperative from presentday mobility research which holds that a society's openness is not to be measured by absolute rates of mobility, but by relative chances of mobility (Goldthorpe, 1980: ch. 3). Relative chances are determined by simply computing so-called odds ratios for two-by-two tables. They are ascertained for Canada, the Netherlands, and the United States in 1981. Three countries are studied, not so much with the purpose of detecting differences between them, but as a means of ascertaining stability of results from country to country.

Data for these three countries have been 
taken from governmental publications on periodical labour force surveys. ${ }^{1}$ Given the international co-ordination of these surveys, results are comparable. All surveys use a threefold classification: employed, unemployed (not employed, looking for work and ready to start), and not in the labour force. Tables have been collected crossing this scheme for husbands and wives. Table 1 gives an example of the type of homogamy table obtained.

To begin with, from tables like Table 1, all couples were eliminated for which one or both partners were outside the labour force. This yielded two-by-two tables crossing (un)employment of husbands and wives. For these tables relative chances of heterogamy were determined: the odds of being employed rather than unemployed for wives of employed husbands, divided by these odds for wives of unemployed husbands. This fraction is called an odds ratio. An odds ratio of 1.00 means that (un)employment of husbands is not related to (un)employment of wives. If an odds ratio is larger than 1.00 , wives of unemployed husbands stand a higher chance of unemployment than wives of employed husbands: unemployed wives to some extent have unemployed husbands, and employed wives employed husbands. If an odds ratio is smaller than 1.00 , wives of unemployed husbands have a smaller chance of unemployment than wives of employed husbands. Odds ratios larger than 1.00 indicate an aggravation of individual labour market inequalities at the level of couples, odds ratios smaller than 1.00 indicate their alleviation.

The (un)employment homogamy table for Canada in 1981 turns out to have an odds ratio of 3.5, that for the Netherlands in this year one of 3.1 , and that for the USA in 1981 an odds ratio of 3.8. As all odds ratios are larger than unity, there is a tendency for employed husbands to have employed wives, and for unemployed husbands to have unemployed wives. Some (un)employment homogamy is found in all three countries in the early 1980 s.

As it has been argued (Flinn and Heckman, 1983) that 'unemployed' and 'outside the labour force' are not behaviourally distinct labour force states, a check was made on this claim. It consisted of adding the number of husbands outside the labour force to the number of unemployed husbands, and number of wives outside the labour force to number of unemployed wives. The odds ratio of the (non)employment homogamy table for Canada turns out to be $4 \cdot 7$, that for the Dutch table 4.7, and that for the USA table $3 \cdot 7$. Since odds ratios remain larger than 1.00 , the earlier conclusion is upheld.

The occurrence of (un)employment homogamy in some Western industrial nations in the 1980s having been established, the next section treats the question of why (un)employment homogamy occurs.

\section{(UN)EMPLOYMENT HOMOGAMY AND EDUCATIONAL HOMOGAMY}

One explanation for homogamy is assortative mating: 'birds of a feather flock together' and 'like chooses like'. Although attractive, it is not correct to apply this explanation to an (un)employment heterogamy table. In the literature this inapplicability has been pointed out as regards the more common tables showing an association between husband's and wife's present occupation in two-earner families. After all, what really counts as a test for assortative mating are data for occupation at time of marriage. It has therefore been held that an association between husband's and wife's present occupation is a product of both assortative mating and reciprocal influence after marriage (Hout, 1982: 398-399). This observation is even more pertinent when analysing (un)employment heterogamy tables: unemployment is a more fleeting characteristic than occupation. Most persons in the tables analysed were married before becoming unemployed. Accepting this observation, it seems possible to explain (un)employment homogamy as a by-product of homogamy with respect to characteristics present before marriage and stable after that. In the light of current research on the relative openness of societies, an obvious variable is education. To make that explanation work, it is necessary to assume that at the individual level education and unemployment are related.

If (un)employment homogamy is a by-product of educational homogamy and of a relation at the individual level between education and 
unemployment, the observed regularity is the addition of an inequality in the labour market and one in the marriage market. Whether these two inequalities are large enough to explain the whole observed phenomenon remains to be seen. If no full explanation is obtained, observed (un)employment homogamy apparently partly results from other processes. Two tests of the by-product hypothesis are performed: one informal, the other more formal via loglinear modelling.

\section{The informal test}

The first step of the informal test is to determine a country's pattern of educational heterogamy. The more unequal the relative chances of educational heterogamy in a country, other factors being held constant, the more unequal the relative chances of (un)employment heterogamy in that country. The second step then ascertains the relationship between education and unemployment for married males and for married females. The stronger the connection between education and unemployment in a country, other factors being held constant, the more unequal the relative chances of educational heterogamy in that country. In the third step, on the basis of the results of steps one and two, a prediction is made of the relation between (un)employment of husbands and wives in an overall table for a country. In the fourth step this prediction is compared with the actual relation in that country.

As an example, Table 2a shows educational heterogamy in Canada in 1981. This table, and similar ones for the Netherlands in 1985 and the USA in $1985,{ }^{2}$ mark the first step of the informal test. They pertain to couples fully in the labour force; those with one spouse, or both, outside it are eliminated. For each country, five educational levels are distinguished. Visual inspection of these tables makes it clear that in all three countries husband's and wife's level of education are to some extent related. Table $2 b$ gives unemployment percentages for married males and married females with different levels of education in Canada in 1981. It shows that the lower a married male or married female's level of education, the higher this person's probability of unemployment. These percentages for Canada, and similar ones for the two other countries featured in this paper, form the second step of the informal test.

The third step then takes the results from steps one and two as given. On the basis of educational heterogamy tables such as Table $2 \mathrm{a}$ and unemployment percentages as from Table $2 \mathrm{~b}$, an (un)employment heterogamy table with statistical independence is constructed for every separate combination of education of husbands and wives. These $5 \times 5=25$ hypothetical tables for one country may be summed into an overall (un)employment heterogamy table. One such overall (un)employment heterogamy table, that for Canada in 1981, is presented in panel (a) of Table 3.

A predicted overall table may display a relation between (un)employment of husbands and wives, which can be expressed by an odds ratio, and this predicted odds ratio may then be compared with that of an actual overall table. The more these odds ratios resemble one another, the more complete is the by-product explanation considered in this section. Note that this is not to say that, if in this test the byproduct explanation to some extent succeeds, the hypothesis of independence in the specific tables has proved its mettle; for instance, it remains possible that in some specific tables odds ratios go in one direction, while those of other specific tables go in another, thus cancelling each other out. The second test described in the next paragraph has more to say on such matters.

The fourth and final step of this informal test consists of just this comparison of predicted overall (un)employment heterogamy tables and actual (un)employment heterogamy tables. The actual table for Canada in 1981 is given in panel (b) of Table 3. According to these tables, the odds ratio of Canada's predicted overall (un)employment homogamy table is 1.0 , while the actual one is 3.4. In addition, for the Netherlands the predicted odds ratio is 1.1 , while the actual one is 4.6 ; and the USA's predicted odds ratio is 1.2 while its actual one is 3.5. Thus, educational homogamy combined with an individual relation between education and unemployment accounts only to a very small 
TABLE 2a Educational heterogamy table for Canada in 1981; couples with one or both spouse(s) not in the labour force deleted ( $N$ of cases set to 1,000, actual number of cases 56,168 )

\begin{tabular}{lccccc}
\hline Husbands & $\begin{array}{c}\text { <9 grade } \\
\text { elem. school }\end{array}$ & $\begin{array}{c}\text { 9-11 grade } \\
\text { elem. school }\end{array}$ & $\begin{array}{c}\text { Wives } \\
12-13 \text { grade } \\
\text { +high school }\end{array}$ & $\begin{array}{c}\text { non-university } \\
\text { qualification }\end{array}$ & $\begin{array}{c}\text { university } \\
\text { degree }\end{array}$ \\
\hline <9 grade elem. school & 63 & 34 & 28 & 12 & 4 \\
$9-11$ grade elem. school & 17 & 59 & 54 & 24 & 8 \\
12-13 grade + high school & 21 & 54 & 151 & 57 & 31 \\
Non-university qualification & 11 & 27 & 69 & 60 & 24 \\
University degree & 2 & 8 & 49 & 42 & 91 \\
\hline
\end{tabular}

TABLE $2 \mathrm{~b}$ Unemployment percentages for Canada in 1981 of married males and of married females by level of education

\begin{tabular}{|c|c|c|c|c|c|c|}
\hline & all & $\begin{array}{l}<9 \text { grade } \\
\text { elem. school }\end{array}$ & $\begin{array}{l}\text { 9-11 grade } \\
\text { elem. school }\end{array}$ & $\begin{array}{l}12-13 \text { grade } \\
\text { elem. school } \\
+ \text { high school }\end{array}$ & $\begin{array}{c}\text { non- } \\
\text { university } \\
\text { qualification }\end{array}$ & $\begin{array}{c}\text { university } \\
\text { degree }\end{array}$ \\
\hline Married males & $3 \cdot 4$ & $6 \cdot 0$ & $5 \cdot 2$ & $3 \cdot 3$ & $2 \cdot 7$ & $1 \cdot 8$ \\
\hline Married females & 7.9 & $10 \cdot 3$ & $9 \cdot 8$ & $8 \cdot 0$ & $6 \cdot 8$ & $5 \cdot 0$ \\
\hline
\end{tabular}

TABLE 3 Predicted (un)employment homogamy table for Canada in 1981 (i.e. as a by-product of educational homogamy and an individual relation between education and unemployment, under an assumption of independence between (un)employment of husbands and wives for all specific combinations of education of husbands and wives); and actual (un)employment homogamy table. (Marginals of predicted and actual tables do not fully correspond due to rounding)

(a) Predicted table

\begin{tabular}{lcc}
\hline Husbands & Employed & $\begin{array}{c}\text { Wives } \\
\text { Unemployed }\end{array}$ \\
\hline Employed & 24,497 & 2,095 \\
Unemployed & 909 & 80 \\
\hline
\end{tabular}

extent for observed (un)employment homogamy in three Western industrial nations in the 1980s.

To check this conclusion, these four steps also have been taken with (non)employment homogamy tables. The earlier conclusion is upheld. For Canada, an odds ratio of 1.2 is predicted, while the actual one is $5 \cdot 2$; for the Netherlands these ratios are 1.2 and 2.5 ; and for the USA 1.3 and $4 \cdot 2$. Although in all three countries husband's and wife's level of education are positively related, and although in all three countries male and female unemployment and nonemployment is higher when an individual's level of (b) Actual table

\begin{tabular}{lrr}
\hline & \multicolumn{2}{c}{ Wives } \\
Husbands & Employed & Unemployed \\
\hline Employed & 24,633 & 1,963 \\
Unemployed & 776 & 209 \\
\hline
\end{tabular}

education is lower, these two relations together are not strong enough to account for (un)employment and (non)employment homogamy.

\section{The formal test}

The by-product explanation of this section rests on the assumption of independence of odds ratios of (un)employment heterogamy tables for specific combinations of husband's and wife's education, and on educational homogamy plus a relationship at the individual level between education and employment. In a more formal test, this explanation may be conveniently modelled 
by incorporating the combined effect of (wife's education $) \times$ (husband's education $) \times($ employment of wife) and that of (wife's education) $\times$ (husband's education) $\times$ (employment of husband).

It is easy to see that in this model all elements of the by-product explanation are included: there is independence between (un)employment of husbands and wives for every combination of husband's education and wife's education, while educational homogamy and the relationship at the individual level between education and employment are explicitly included. This formalization of the by-product explanation will be applied to (un)employment as well as to (non)employment heterogamy tables.

Fits of the above-mentioned loglinear model for Canada, the Netherlands and the USA, are presented in Table 4, panel (a), under the heading of 'model 1'. These fits are to be compared with those of a model with the effects of model 1 plus the two-way effect of (husband's employment) $\times$ (wife's employment). Fits for the latter model for the three countries of this paragraph are given in Table 4, panel (a), under the heading of 'model 2'. Comparison of fits makes it clear that model 1 , a formalization of the by-product explanation, is to be rejected. Model 1 does not fit; model 2 always fares decidedly better and in most cases does fit. Moreover, according to Table 4, panel (b), this conclusion also holds for (non)employment homogamy in Canada, the Netherlands and the United States. Model 2 receives a more elaborate interpretation in the following section.

\section{(UN)EMPLOYMENT HOMOGAMY FOR SPECIFIC COMBINATIONS OF EDUCATIONAL LEVELS FOR HUSBANDS AND WIVES}

Given the above findings, the following question may be raised. What do actual odds ratios look like for specific combinations of educational levels for husbands and wives? Are all actual partial odds ratios equal, or do they differ? Before partial odds ratios are reviewed, some hypotheses are presented predicting different odds ratios for different combinations of education for husbands and wives.

Becker's economics of the family has made it
TABLE 4 Loglinear models testing a by-product explanation of (a) (un)employment homogamy and (b) (non)employment homogamy tables for Canada in 1981, the Netherlands in 1985 and the USA in 1985

\begin{tabular}{lcrc}
$\begin{array}{l}\text { (a) (Un)employment homogamy } \\
\text { Country }\end{array}$ & Model & $\mathrm{G}^{2}$ & df \\
\hline Canada & 1 & 183 & 25 \\
& 2 & 21 & 24 \\
Netherlands & 1 & 481 & 25 \\
& 2 & 18 & 24 \\
USA & 1 & 136 & 25 \\
& 2 & 39 & 24 \\
\hline
\end{tabular}

(b) (Non)employment homogamy

\begin{tabular}{lcrl} 
Country & Model & $\mathrm{G}^{2}$ & df \\
\hline Canada & 1 & 3,199 & 25 \\
& 2 & 63 & 24 \\
Netherlands & 1 & 869 & 25 \\
& 2 & 94 & 24 \\
USA & 1 & 2,010 & 25 \\
& 2 & 33 & 24 \\
\hline
\end{tabular}

model 1:

(education husband $) \times$ (education wife $) \times($ employment husband $)+$ (education husband $) \times($ education wife $) \times$ (employment wife)

model 2:

model $1+($ employment husband $) \times($ employment wife $)$

clear that some division of labour between married couples is to be expected, not only because of tradition (the usual explanation), but also when spouses are rational. If comparative advantages of homework and job-activity differ between spouses, 'gains from trade' are achieved (Becker, 1981: ch. 2): Although Becker's economics of the family also predicts some assortative mating (Becker, 1981: ch. 4), until now no specific predictions have been derived within 'the new home economics' (cf. Berk and Fenstermaker, 1983) about the consequences of educational differences between spouses for the division of labour between them. This section derives such predictions, after which they are empirically tested.

In Becker's theory, individuals are not the unit of analysis, but households-here assumed to consist of couples. To derive predictions, 
several assumptions are necessary. It is assumed that couples have been constituted, that both partners have held jobs before marriage, and that a joint decision is made on who will have a job. (The possibilities that both persons have a job, or both have no job, are not ruled out.) Also assume that the comparative advantages of housework for males are equal to those for females. In addition, assume that the higher an individual's level of education, the higher this person's job income. Assume, too, that all unemployment is voluntary, so that 'unemployment' and 'not in the labour force' may be collapsed into 'nonemployment'. Finally, assume that the number of fully nonemployed couples, being mainly determined by specific old age pension provisions, is independent of education of husband and wife.

Now take a couple with both spouses having the highest level of education, and a couple with one spouse having the highest level and the other the next highest. Given the relation between education and income, the relative loss in income for the first couple of the decision that one partner or the other will specialize in household production is larger than the relative loss of income for the second couple of the decision that the partner with less education will specialize in it. (The possibility that the spouse with the highest education will specialize in housework is immediately ruled out.) If decisions of couples are based on relative job income losses (cf. Kapteyn, 1985 on habit formation), the first couple will have a higher probability of turning into a two-earner family than the second couple. This argument may be extended to couples in which one spouse has the highest level education and the other any lower level, and to couples in which the firstmentioned partner has less education than the highest level.

The above line of reasoning implies that the odds ratio of a (non)employment homogamy table for educationally homogamous couples is higher than that for educationally heterogamous couples. In addition, the larger the differences in education between partners, the lower are the odds ratios for these couples. Also, for every type of homogamous couple, whether their education is high or low, odds ratios are identical.
The argument has so far implicitly assumed that returns to education for husbands and wives are similar. If, more realistically, it is held that for males and females with the same education, returns to education are higher for males than for females, more precise predictions about odds ratios for specific (non)employment homogamy tables become possible. Lower returns for females make for more female nonemployment. This holds more strongly in couples where wives have less education than their husbands, and less strongly in couples where they have more education than their husbands. Starting from couples with different educational levels, in couples where females have the lower educational level, odds ratios will be lower than in couples where females have the higher educational level.

It now is possible to return to the question whether within Canada, the Netherlands and the USA in the early 1980 s there is a similarity or dissimilarity of odds ratios for (non)employment heterogamy tables pertaining to specific combinations of education of husbands and wives. The dissimilarity prediction from the new home economics is in fact rejected by a loglinear model applied in the previous section: i.e. model 2 in Table 4, which included the two-way effect (employment husband) $\times$ (employment wife). This effect embodies the hypothesis that all odds ratios for all combinations of education of husbands and wives are equal, and, according to the $\mathrm{G}^{2} \mathrm{~s}$ reported in Table 4, panel (a), model 2 fitted, or almost fitted, (un)employment data for Canada, the Netherlands and the USA alike.

It is, of course, difficult to say which of the assumptions made above should be changed after these negative pieces of evidence. A major candidate is the assumption that labour market status is determined by relative income losses, which is not a very orthodox assumption within new home economics. Yet it remains a plausible one. Another major candidate is the assumption that all unemployment is voluntary. But before making new predictions about the degree of (non)employment homogamy for specific combinations of education for husbands and wives, it might be useful to consider actual patterns of odds ratios in this case. According to Table 4, panel (b), models of identical odds ratios for 
(non)employment data come close to providing a good fit. Given these findings, efforts to derive predictions from the new home economics may be abandoned. Possibly the new home economics, when properly elaborated, predicts equal odds ratios for (un)employment and (non)employment homogamy tables for specific combinations of education for husbands and wives. It might, however, be remembered that most odds ratios in Table 4 are far above unity, thus underlining the conclusions that were reached in the last section.

\section{(UN)EMPLOYMENT OF HUSBANDS AND WIVES: DO COUPLE EFFECTS PERSIST?}

Now an attempt is made to account for (un)employment homogamy not only by husband's and wife's level of education, but also by their age and by the percentage of unemployment in their area of residence. The question is not simply whether educational, age and residence homogamy, and individual relations between education, age and residence on the one hand and employment on the other hand, do lead to (un)employment homogamy. The question goes further since it asks to what extent observable (un)employment homogamy may be accounted for in this way. That is, apart from the size of these three side-effects, the size of other-as yet unspecified-effects is determined. If some (un)employment homogamy remains unaccounted for, apart from an aggravation of labour market effects by marriage market effects, other effects are present. These effects presumably emanate from interaction between partners after marriage. They are called couple effects. Although it makes sense to ask whether the phonomenon of (un)employment homogamy disappears when allowing for effects of age, education and region, it is not immediately clear how this question is to be tackled technically. In line with the analysis of earlier sections, one may consider odds ratios for (un)employment heterogamy tables for specific combinations of husband's and wife's education, of husband's and wife's age, and of husband's and wife's residence. Yet this is only a partial answer. When assessing these effects simultaneously rather than separately, odds ratios become un- stable because of the limited number of cases for each combination. Secondly, without precise hypotheses about patterns of odds ratios (the previous section led to a rejection of one such hypothesis), there is not much to interpret. The following alternative circumvents these difficulties.

According to the by-product explanation to be considered here, an individual's (un)employment is determined by age, education and residence. Although there is an association between a person's age, education and residence, and these characteristics for the person's spouse, according to the by-product explanation envisaged, these characteristics of spouse do not influence the person's (un)employment. This argument implies that the respective 'residuals' of (un)employment for husbands and wives, after allowing for their age, education and residence effects, must be uncorrelated. In contrast, (un)employment homogamy is demonstrated if the correlation between the residuals, after allowing for individual effects, does not vanish. More generally, the correlation between residuals can be considered as a corrected estimate of (un)employment homogamy. This line of reasoning boils down to the model depicted in Figure 1 . It might be noted that this model somewhat resembles Hauser and Mossel's (1985) perhaps more familiar 'kinometrics' models for siblings.

Because of data limitations (no tapes were available for Canada and the Netherlands), correlations between residuals have only been

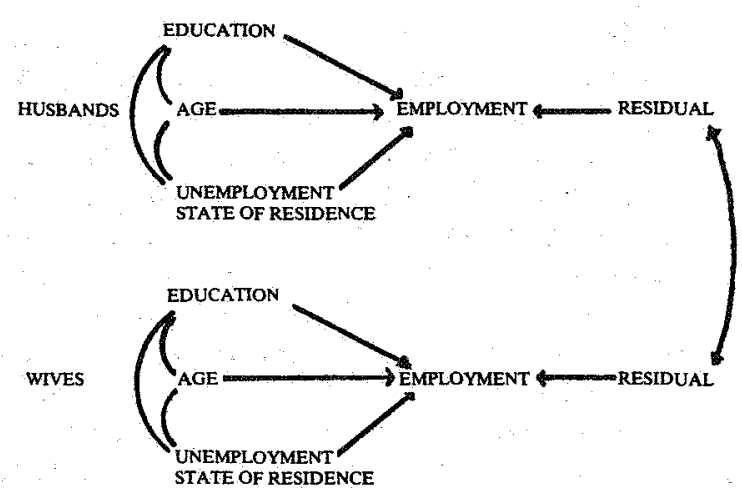

FIGURE 1 Separate logit models for husbands and wives in order to demonstrate (un)employment homogamy. 
computed for the USA, March 1985 data. As no data about nonemployment in the separate states of the USA were available, estimates pertain to (un)employment homogamy only. The number of couples having a missing value on the residence variable is quite high, 61 per cent to be exact. (Apparently privacy considerations are at work here.) These couples were deleted from the analysis. Couples with at least one spouse outside the labour force were also deleted. This left 6,764 unweighted cases.

Data on the percentage of unemployment for the separate states of the USA in March $1985^{3}$ were used to produce nominal codes for name of state of residence in the computer tape analysed. This variable had six categori $\uparrow$. The unemploy ment rate (up to one decimal) was divided by two, and subtracting one from the integer part of this fraction turned out to give six scores only. Age was also recoded into six categories: less than 20 years, 20 to 30 years, 30 to 40 years, 40 to 50 years, 50 to 60 years and 60 years or more. Educational categories were the same as in earlier analyses.

The computation of correlations between residuals was made in five steps. In the first step, the total number of persons for each combination of age, education and residence was calculated separately for husbands and wives, and for each combination the fraction employed.

In the second step, the probability of employment for four nested logit models was estimated. Logit analysis was used to circumvent extreme marginal skewness. It may be added that logit analysis is akin to loglinear analysis, but is better suited to the asymmetric character of the data (age, education and residence precede employment). The first model contains only the general mean, and assumes no effect of age, education or residence. The last (saturated) model allows for the effects of age, education, region and all possible interactions between these variables. These two models provide benchmarks for interpreting later results. The two models in-between are of substantive interest. One fits effects of education and residence, the other the effect of residence and of an interaction of education and age. As fits of these models are not pertinent, they are not presented.
In the third step, the estimated probabilities of employment for husbands and wives for each of the four models were entered into the original data matrix for 6,764 couples. Then, in the fourth step, residuals were calculated; that is, a person's actual employment score minus this person's estimated probability of employment. Finally, in the fifth step, covariances and product-moment correlations between corresponding residuals for husbands and wives were calculated. Since four residuals per person were computed, one for each logit model, four covariances and correlations were obtained.

Covariances and product-moment correlations, as well as odds ratios, describe the level of (un)err-loyment homogamy in an (un)employment heterogamy table. Indeed, there is a remarkable relationship between odds ratios and covariances. In a two-by-two table with $a, b$, $\mathrm{c}$, and $\mathrm{d}$ as the respective cell frequencies, the odds ratio is $\mathrm{ad} / \mathrm{bc}$, while the covariance is ad-bc. In the actual USA (un)employment heterogamy table, the odds ratio is 3.6 , the covariance 0.0064 and the correlation 0.1120 .

Table 5 presents covariances and correlations between comparable residuals of (un)employment for husbands and wives, together with variances of residuals for husbands and for wives. The covariance and correlation of residuals obtained with the logit model for the general mean is necessarily equal to the covariance and correlation by which the US (un)employment heterogamy table was just described. If effects of age, education and residence and all possible interactions between those variables are taken into account, the covariance between the corresponding residuals drops from 0.0064 to 0.0051 , and the correlation from 0.1120 to 0.0915 . This reduction of about 20 per cent leads to the conclusion that the observed level of (un)employment homogamy is only partly explained by age, education and unemployment level. In other words: coupleeffects are still present.

\section{DISCUSSION}

In 1982 the Organisation for Economic Cooperation and Development published a report to Labour Ministers of its member countries con- 
TABLE 5 Variances of residuals for husbands $(x)$ and wives $(y)$ based on four logit models for employment, and covariances and correlations between corresponding residuals for husbands and wives

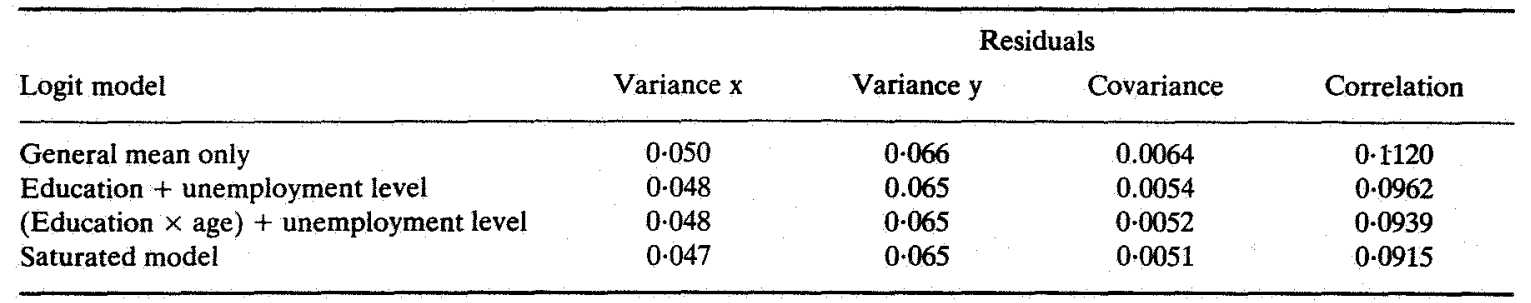

taining a paragraph on the 'family incidence of unemployment' and a square table from the March 1980 USA Current Population Survey crossing employment status of husbands and wives. One comment on this table ran as follows (OECD, 1982: 36).

'One striking feature ... is the apparenr concentration of unemployment within families, indicated by the high unemployment rate of wives of unemployed husbands. This phenomenon is probably caused by several factors including the fact that husbands and wives are generally subject to the difficulties of the same local labour markets and, perhaps, by a certain tendency for persons of . relatively low employability (in terms of skill levels, etc.) to be found together in the same family. The high unemployment rate of wives of unemployed husbands may also be related to the fact that they may be forced to seek work because of their husband's unemployment and may thus enter the labour market when jobs are scarce and on less advantageous terms.' These interpretations of an (un)employment homogamy table remained untested in that OECD study.

This paper has established that in the early 1980 s the unemployment of husbands and wives went hand in hand not only in the USA, but also in Canada and the Netherlands. This relationship is not explained by invoking changes for wives from the state of outside the labour force to the state of unemployment. (Non)employment homogamy tables displayed the same relationship.

This paper has also shown that a relation between husband's and wife's education-education being an indicator of their skill level-and an individual relation between education and employment only very partially account for observed (un)employment and (non)employment homogamy. This conclusion was obtained for all three countries. The conclusion that educational homogamy and an individual relation between education and employment do result in some (un)employment and (non)employment homogamy, implies that a labour market inequality (the relation between education and employment) is aggravated by a marriage market inequality (educational homogamy).

For the USA in 1985, this paper has further shown that the percentage of unemployment in a couple's state of residence-an indicator of local labour market conditions-makes for (un)employment homogamy. Age homogamy and an individual relation between age and employment-a factor not mentioned in the OECD interpretation-do so too. Yet these two sideeffects, together with that of educational homogamy and an individual relation between education and employment, still do not fully account for all observed (un)employment homogamy. Consequences are present that might be termed couple effects: effects that arise from interaction between partners after marriage.

This paper's answer to the question of why unemployment comes in couples has been largely negative. By-product explanations turned out to be very partial, and an application of a new home economics explanation proved unfruitful. Although other explanations may be devised within new home economics, no such proposals will be developed here. Yet on several counts this study has pressed further forward than earlier ones in comparable fields.

In a recent report on the association between 
husbands' and wives' occupations in two-earner families, Hout stated that a decomposition of the association between husbands' and wives' occupational statuses into the portion arising from assortative marriage and the portion due to status constraints on occupational placement (i.e. between effects of family formation and those of the stratification process per se) was beyond the scope of that study (Hout, 1982: 399). For (un)employment and for (non)employment tables, this paper has attempted such a decomposition. In this way, the paper has shown the need for more differentiation within the category of family formation effects. There are effects of assortative marriage, that is, of characteristics fixed before marriage, the main ones being education and age. But apart from these effects, there are those of processes taking place after marriage. Some effects are the outcome of marriage markets, other effects are due to interaction between spouses.

In the case of occupational homogamy in two-earner families, Hout suggested three processes taking place between spouses after marriage: individuals may rule out possibilities too different from their spouses' occupations, information about employment possibilities brought home by one employed spouse may steer job seekers toward related occupations, and larger status differences between spouses may lead to marital disruption (Hout, 1982: 398, n. 2). Although the findings of this paper attest to the importance of these and related factors in answering questions about (un)employment and (non)employment homogamy, these factors have not been explicitly measured. The determination of their precise effects is beyond the scope of existing data sets. Yet this paper suggests a way of decomposing the association between husbands' and wives' occupations in two-earner families. If it is assumed that the education of spouses is determined before marriage, an association between husbands' and wives' occupations beyond that expected by educational homogamy and an individual relation between education and occupation is indicative of the importance of the third category of factors. This analysis is within reach with existing data sets.

The finding that couple effects exist, after eliminating effects of husband's and wife's education, age and residence, was only made for the USA. This finding stands in need of replication, as it was obtained from a relatively low number of cases, with a high percentage of missing values on the residence variable. Hopefully, by combining more complete USA data sets for different years, it will be possible to replicate it. In addition, the finding should be replicated for other countries. Whether data sets for other countries are available with which replication may be undertaken is at this moment not known.

The analysis was performed on existing data sets. It is quite likely that similar ones exist for countries not covered by this study. This makes comparative analysis of (un)employment homogamy a definite possibility. In this paper the analysis of data for three countries was simply a means of checking the stability of results. By way of comparative analysis, such questions may be answered as to what extent the conventional ranking of Western industrial nations according to their relative chances of class mobility, or their relative chances of educational homogamy, is in line with their ordering according to (un)employment homogamy. In this way, questions about the 'openness' of societies may be broadened so as to include newly emerging aspects of their stratification.

\section{NOTES}

1. Data for Canada from Statistics Canada (1986), data for the USA from US Department of Labor (1982). The Dutch 1981 table was run on request by the Dutch Centraal Bureau voor de Statistiek, Voorburg. Ns for all three tables are several 10,000 s.

2. Data for Canada are from a 1 per cent public use sample of the 1981 Canadian Census, made available in tabular form by the Institute for Social Research, University of York. A four-way classification was obtained: employment status of husband and employment status of wife by education of husband by education of wife. The number of cases (couples) was 56,168. Data for the Netherlands were made available by the Centraal Bureau voor de Statistiek, Voorburg, and are from the Spring 1985 Labour Force Survey (cf. Bakker, 1987). A fourway classification similar to that for Canada was obtained. The number of couples was 67,362. Data for the USA were from the Current Populations Survey, Annual Demographic File, March 1985. The file was obtained from the Interuniversity Consortium for Political and Social Research in Ann Arbor, Michigan. 
The number of couples selected from this file was (before weighing) 35,614 . The educational classification for Canada is given in Table 2. The educational classification for the Netherlands was (1) primary school, (2) lower secondary school, (3) upper secondary school, (4) higher vocational school, (5) university. The educational classification the USA was (1) elementary school, (2) 1 to 3 years high school, (3) 4 years high school, (4) 1 to 3 years university, (5) 4 years or more university.

3. Data were taken from US Department of Labor (1986).

\section{ACKNOWLEDGEMENTS}

An earlier version of this paper was presented at the meeting of the International Sociological Association's Research Committee on Social Stratification, August 12-15 1987 at the University of Cálifornia, Berkeley. Special thanks to Albert Verbeek, Faculty of Social Sciences, University of Utrecht, for his constructive ideas and practical help and also to Bart Bakker, Central Bureau of Statistics, The Hague.

\section{REFERENCES}

Bakker B F M. (1987): Betekenis, operationalisering en meting van sociale afstand, Voorburg: Centraal Bureau voor de Statistiek, Hoofdafdeling Sociale Rekeningen, BPA no. 13601-S7-87.

Becker G S. (1981): A treatise on the family, Cambridge Mass.: Harvard University Press.

Berk R A, Fenstermaker Berk S. (1983): 'Supply-side sociology of the family: the challenge of the new home economics', Annual Review of Sociology, 9: 375-395.

Flinn C, Heckman J. (1983): 'Are unemployment and out of the labor force behaviorally distinctive labor force states?', Journal of Labor Economics, 1: 28-42.

Glass D V. (ed) (1954): Social mobility in Britain, London: Routledge.
Goldthorpe J H. (1980): Social mobility and class structure in modern Britain, Oxford: Clarendon Press.

Grusky D B, Hauser R M. (1984): 'Comparative social mobility revisited: models of convergence and divergence in 16 countries', American Sociological Review, 49: 19-38.

Hauser R M, Mossel P M. (1985): 'Fraternal resemblance in educational attainment and occupational status', American Journal of Sociology, 91: 650-673.

Hout M. (1982): 'The association between husbands' and wives' occupations in two-earner families', American Journal of Sociology, 88: 397-409.

Kapteyn A. (1985): 'Utility and economics', De Economist, 133: 1-20.

Miller S M. (1960): 'Comparative social mobility', Current Sociology, 9: 1-89.

OECD (1982): The challenge of unemployment, a report to labour ministers, Paris: OECD.

Payne J. (1987): 'Does unemployment run in families? Some findings from the General Household Survey', Sociology, 21: 199-214.

Statistics Canada. Labour and Household Surveys. Analysis Division (1986): Family characteristics and labour force activity: annual averages 1977-1984, Ottawa: Ministry of Supply and Services.

US Department of Labor. Bureau of Labor Statistics (1982): Employment and earnings, January.

US Department of Labor. Bureau of Labor Statistics (1986): Employment and earnings, May.

\section{AUTHORS' ADDRESS}

Wout Ultee, Jos Dessens and Wim Jansen, University of Utrecht, Faculty of Social Sciences, Postbus 80:140, 3508 TC Utrecht, The Netherlands. 